\title{
Editorial
}

\section{Our healthier nation: alpha for presentation, beta minus for deliverability}

This is a bold document, in both the negative and the positive senses of the word "bold". Sir Humphrey Appleby would have viewed it as politically lunaticafter all it proposes quantified targets for health improvement starting from specific, unambiguous baselines, hence launching chickens that will one day come home to roost-and would no doubt have dissuaded the secretary of state from publication. ${ }^{1}$ On the other hand, the government is to be congratulated for the courage, vision, and clarity of what is among the best documents of its kind yet produced - not merely here, but overseas. Deliverability is another matter.

The merits of the green paper are conceptual, strategic, and presentational. Conceptually, it is powerful, in the tradition of Marc Lalonde's classic $A$ new perspective on the health of Canadians. ${ }^{2}$ The latter, published in 1974, was the first national strategy-at least in modern times - to be based on the concept that health depends at least as much on human biology, the environment and lifestyle, as it does on the efforts of health services. Our healthier nation takes a similar framework, adding social and economic factors as a fifth dimension. ${ }^{3}$ It also recognises the importance of different settingsschools, workplaces and neighbourhoods-as areas for action agreed between government and local communities (although this begs the question, "what about those who are out of work and socially excluded?"). Crucially, the government is taking health inequalities seriously and is committed to reducing them. That has to be right. The increasing gap between the haves and have nots is one of the least attractive features of Britain in the 90 s.

Strategically, the green paper selects four targets (which is quite enough) along with the reduction of inequalities. The four are heart disease/stroke, accidents, cancer, and mental health. For once, the government has not sought to score party political points by rubbishing the previous administration's The health of the nation, ${ }^{4}$ but is largely prepared to adopt the same priorities. (The exception is sexual health, which has dropped out of the priorities for action, for no very obvious reason.) While the continuity from the previous government's health promotion strategy is even clearer in the Scottish consultation document, Working together for a healthier Scotland, ${ }^{5}$ than it is in the English one, the latter can also be seen as a direct successor to Virginia Bottomley's similar initiative. That is very much to be welcomed within the NHS, for too much managerial effort has been absorbed by politically inspired organisational changes, and too little by the sustained drive to improve health. It is high time to grow up and to recognise that health gain ought to be above party political ideologies, and that it calls for sustained action beyond the lifetime of most administrations.

Presentationally, the document is well done. It is simply and clearly written, with good graphics and with some useful examples of service innovations that illustrate how elements of the strategy can be implemented locally. Less clever is the "tear out" section at the end, inviting comments. To allow two lines for comment on an enormous topic, such as how can public health research be strengthened, smacks of tokenism, not a real interest in feedback.

So, what are the more substantive deficiencies? Firstly, at the strategic level there is at this stage (as ministers would acknowledge) a total lack of objectives around reducing inequalities, and of commissioning strategies for doing so. Of course, the Acheson Inquiry is currently tackling that complex set of issues and it is clearly logical to wait for its findings, ${ }^{6}$ provided that they are incorporated into the government's strategy before the latter is finalised. Within each of the four disease/problem orientated programmes there ought to be some targets that are about reducing inequalities-for example, in the case of accidents, drastically lessening the fivefold difference in fatal accidents in childhood between poor and rich-even if some targets for greater equality also cut across programmes.

Secondly, while the disease/problem approach is all very well at the level of high potential strategy, I am by no means convinced that it works at the operational level. For example, smoking is the major contributory factor in some cancers, as well as being significant for heart disease and stroke. Rather than being an entry in these two programmes, should not smoking reduction be a prime target-justified of course by its impact on these diseases, but itself the focus of a national strategy? The same applies to alcohol, drugs, exercise, diet. All these are sufficiently substantial influences on disease and mortality that we ought to have national and local strategies for each of them. If we do, and if we carry them through, the impact on disease targets is pretty much guaranteed. Unless we are clear about this, the disease-based strategies are likely to be repetitive, relatively feeble, and quite possibly unsuccessful. An example from The health of the nation is the target of obesity reduction, where the national strategy has clearly failed.

Thirdly, an admittedly narrow but nevertheless important point, I am by no means persuaded that the government's proposed mental health target, to reduce death rate from suicide and undetermined injury by at least 17 per cent by the year 2010, is either achievable or (on its own) an adequate measure of mental health care. For it to be so, it would have to be a good surrogate measure of care for a wide range of mental conditions, and I know of no evidence that it is.

Finally (and I accept that the green paper is the starting point for a consultation process, not a blueprint for action), far too little attention is given in this document to what might work at either the local, or indeed the national, level. As Tolstoy remarked in War and Peace a good strategy is all very well, but what actually happens on the battlefield is 
remarkably different and less coherent. An adage for barristers is not to ask questions in court, unless they know the answers. A managerial equivalent is not to set a corporate objective without having a pretty shrewd plan for implementing it. Currently that plan is lacking.

Dursley, Gloucestershire
ROBERT J MAXWELL
1 Lynn J, Jay A. The complete yes minister: The diaries of a cabinet minister. London: Guild Publishing, 1984

2 Lalonde M. A new perspective on the health of Canadians. Government of Canada, 1974

3 Department of Health. Our healthier nation: a contract for health. London: The Stationery Office, 1998.

4 Department of Health. The health of the nation. London: HMSO, 1992.

5 Scottish Office. Working together for a healthier Scotland. Edinburgh: The Stationery Office, 1998

6 The independent inquiry into health inequalities. Chaired by Sir Donald Acheson. (In press).

\section{$\mathrm{JECH}$ and the world wide web}

Visitors to the world wide web can now access the fournal of Epidemiology and Community Health either through the BMJ Publishing Group's home page (http://www.bmjpg.com) or directly by using its individual URL (http://www.jech.com). There they will find the following:

- Current contents list for the journal

- Contents lists of previous issues

- Members of the editorial board

- Subscribers' information

- Instructions for authors

- Details of reprint services.

Hotlink

A hot link gives access to:

- BMJ Publishing Group home page

- British Medical Association website

- Online books catalogue

- BMJ Publishing Group books.

\section{Suggestions welcome}

The website is at a preliminary stage and there are plans to develop it into a more sophisticated site. Suggestions from visitors about features they would like to see are welcomed. They can be left via the opening page of the BMJ Publishing Group site or, alternatively, via the journal page, through "about this site". 